\title{
Jacques Houriez, Paul Claudel ou les tribulations d'un poète ambassadeur. Chine, Japon, Paris
}

\section{Simonetta Valenti}

\section{(2) OpenEdition}

1 Journals

\section{Edizione digitale}

URL: https://journals.openedition.org/studifrancesi/3202

DOI: 10.4000/studifrancesi.3202

ISSN: 2421-5856

\section{Editore}

Rosenberg \& Sellier

\section{Edizione cartacea}

Data di pubblicazione: 1 juillet 2013

Paginazione: 484-485

ISSN: 0039-2944

\section{Notizia bibliografica digitale}

Simonetta Valenti, «Jacques Houriez, Paul Claudel ou les tribulations d'un poète ambassadeur. Chine, Japon, Paris», Studi Francesi [Online], 170 (LVII | II) | 2013, online dal 30 novembre 2015, consultato il 02 février 2023. URL: http://journals.openedition.org/studifrancesi/3202 ; DOI: https://doi.org/10.4000/ studifrancesi.3202

\section{Questo documento è stato generato automaticamente il 2 février 2023.}

\section{(c) 9 (1) $\Theta$}

Creative Commons - Attribuzione - Non commerciale - Non opere derivate 4.0 Internazionale - CC BYNC-ND 4.0

https://creativecommons.org/licenses/by-nc-nd/4.0/ 


\title{
Jacques Houriez, Paul Claudel ou les tribulations d'un poète ambassadeur. Chine, Japon, Paris
}

\author{
Simonetta Valenti
}

\section{NOTIZIA}

JACQUES HOURIEZ, Paul Claudel ou les tribulations d'un poète ambassadeur. Chine, Japon, Paris, Paris, Champion, 2012 («Poétiques et Esthétiques xxe-xxI siècles», 7), pp. 366.

1 Il volume di Jacques Houriez getta luce su alcuni episodi tuttora poco noti della vicenda umana e professionale di Paul Claudel, permettendo di fare emergere la poliedrica personalità dello scrittore, sia in rapporto all'attività diplomatica da lui svolta, sia in relazione alla sua vasta produzione poetica e drammaturgica.

2 Houriez coglie con intelligenza le numerose contraddizioni che contraddistinguono il genio claudeliano, sempre teso a conciliare in sé istanze affatto lontane, quando non antitetiche: il piacere del mondo e l'anelito alla spiritualità, il desiderio della felicità terrena e il richiamo dell'eternità, l'impulso egoistico a realizzarsi da solo e l'imprevedibile appello del Divino, le esigenze della carriera diplomatica e quelle dell'affermazione nel campo delle lettere, l'esilio nelle lontane terre d'Oriente e la volontà di essere presente sulla scena letteraria parigina del primo Novecento; infine, la spontaneità di uno stile carico di immagini e di echi biblici e l'esigenza di incanalare il magmatico sorgere delle metafore all'interno di un verso che segua e riproduca fedelmente i moti più reconditi dell'animo.

3 L'elemento biografico si presenta allora quale trampolino necessario, ma non indispensabile, per comprendere l'evoluzione della concezione estetica di Claudel, che mai sazio di ciò che aveva compreso della vita e dell'arte - perseguì sempre il desiderio di rinnovare il proprio stile, integrandovi le riflessioni che andava elaborando sul senso della Storia e le tecniche drammaturgiche che andava via via scoprendo e 
sperimentando, anche a contatto con altre esperienze teatrali, quali il teatro popolare cinese e, più tardi, il Nô giapponese.

Dalla mirabile sintesi di tradizioni artistiche così diverse da quelle occidentali, oltre al teatro shakespeariano, a quello di Eschilo, a quello del Secolo d'Oro spagnolo, ma altresì a quello simbolista, dai quali egli ha comunque attinto ispirazione, Claudel ha saputo trarre nuova linfa per la creazione di un teatro assolutamente originale, innovativo e d'avanguardia, come è emblematicamente dimostrato in opere quali Le Soulier de satin (1929), Jeanne d'Arc au bûcher (1939) o Le Livre de Christophe Colomb (1937). In esse, realtà e finzione si mescolano e si compenetrano, dando vita infatti a un teatro che, affermando con forza l'illusione drammatica, ne esalta la funzione di "parabola", ovvero di strumento della ricerca e del disvelamento del senso ultimo dell'esistenza umana. Sono precisamente tale ricerca e tale disvelamento che fanno sì che il teatro di Paul Claudel ci sorprenda ancora oggi per la sua straordinaria, vitalissima capacità di parlare di noi. 